\title{
Bridging osteophyte of the anterosuperior sacroiliac joint as a cause of lumbar back pain
}

\author{
K A Parmar, M Solomon, A Loefler, S Dalton
}

Br J Sports Med 2004;38:e33 (http://www.bjsportmed.com/cgi/content/full/38/6/e33). doi: 10.1136/bjsm.2004.011536

A case report is presented of a patient with an anterosuperior osteophytic bone bridge of the sacroiliac joint causing lumbar back pain. After prolonged physiotherapy, the bone bridge was excised, with complete resolution of the symptoms. Excision should only be considered in cases of symptomatic sacroiliac joint pain that does not respond to rehabilitation programmes and conservative treatment.

\section{CASE REPORT}

A 33 year old man presented with a three month history of worsening lumbar back pain while performing leg press exercises in the gymnasium. He continued to train for the next two weeks but the pain deteriorated, with radiation to the left buttock, posterolateral thigh, and calf. Symptoms were aggravated by running and prolonged sitting and standing.

Abnormal findings on examination were: reproduction of gluteal, posterolateral thigh and calf pain on sciatic nerve stretching; lumbar back pain on loading the lumbar facet joints to the left (by hyperextension and rotation to the left); pain on palpation of the left gluteal region.

The clinical diagnosis made was left lower lumbar facet joint osteoarthritis with increased gluteal muscular tightness and sciatic nerve irritability. He was initially treated with physiotherapy, concentrating on core stability exercises and gluteal muscle releases.

Investigations included a radiograph of the lumbosacral area, showing mild facet joint osteoarthritis, and a magnetic resonance imaging scan, showing no abnormal disc or nerve root pathology. Computed tomography (CT) scanning of the lumbosacral region revealed a large bridging osteophyte across the anterosuperior aspect of the left sacroiliac (SI) joint (fig 1). This was initially thought not to be contributing to his symptoms.

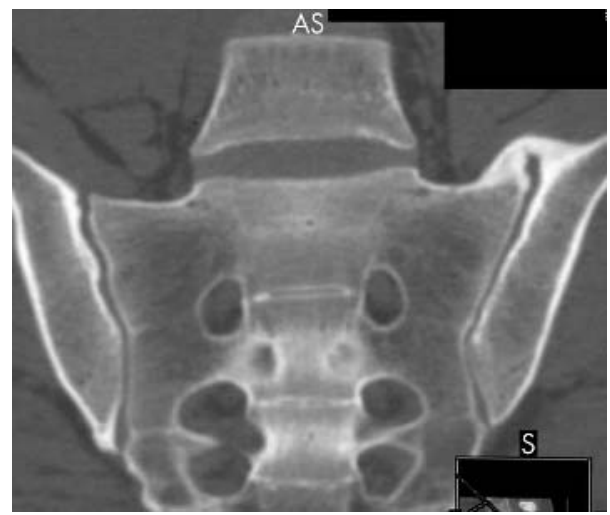

Figure 1 Computed tomography scan of the lumbosacral region showing a large bridging osteophyte across the anterosuperior aspect of the left sacroiliac joint.

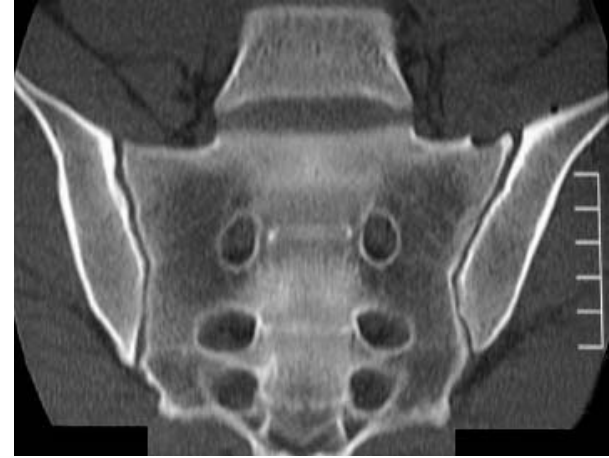

Figure 2 Computed tomography scan showing complete excision of the bony bridge.

After six weeks of physiotherapy, pain localised to the left lumbar 4,5 (L4,5) facet joint and left SI joint. CT guided cortisone injection into the left $\mathrm{L} 4,5$ facet joint produced some relief of symptoms although SI joint symptoms remained.

During two years of physiotherapy, the pain became localised to the left SI joint region, with a large component of the lumbar pain considerably improved. A bone scan was performed which showed increased uptake in the left L4,5 facet joint and left SI joint regions. It was felt that the remaining symptoms were from the bridging osteophyte of the left SI joint. Corticosteroid injections into the anterosuperior SI joint were considered too difficult because of the risk of damage to intra-abdominal contents, and he was subsequently referred for an excision of the bony bridge.

\section{SURGICAL PROCEDURE}

The pelvis was entered through a subperiosteal dissection based over the posterior iliac crest. The SI joint was identified and the bridging osteophyte was visualised. No movement of the SI joint was noted. The bridging osteophyte was excised using a high speed burr and the SI joint was subsequently noted to have micro-movement.

\section{POSTOPERATIVE COURSE}

The pain had improved dramatically within 24 hours of the operation. A postoperative CT scan showed complete excision of the bony bridge (fig 2). After nine months, the patient was largely symptom free with only mild low back pain from the L4, 5 facet joint osteoarthritis.

\section{DISCUSSION}

Shibata et ll $^{1}$ investigated the natural history of aging on the SI joint. Their study showed that joint degeneration begins in the 20s and tends to progress with age. Osteophytes were

Abbreviations: $\mathrm{CT}$, computed tomography; $\mathrm{SI}$, sacroiliac 
found on the anterior surface of the sacrum. Osteophytes of the SI joint are common. In the cadaveric study by Vogler et $a l^{2}$ the incidence was $17 \%$ at age 30 reaching $60 \%$ at age 60 . They are more common in men than women, and, when present unilaterally, there is a predilection for the right side. Male joints are built for strength; the osteophytes are situated at the superior part of the SI joint, which is the line of weight transmission from the axial skeleton to the lower limb. Female joints are more mobile to facilitate parturition. The stress produced by this mobility is concentrated at the inferior aspect of the SI joint, explaining the presence of osteophytes in this region. ${ }^{3}$

Kumar et al described four cases of sciatica due to osteophytes impinging on the sciatic nerve. These osteophytes were found at the inferior border of the SI joint encroaching within the greater sciatic notch. Surgery was performed in two of the four cases producing resolution of the symptoms.

Plain films of the SI joint have traditionally been the screening procedure of choice for SI joint disease. ${ }^{2}$ The anatomical complexity of the joint makes visualising all parts of the undulating joint space difficult. In patients with a suspicious clinical history, but negative radiographic findings, CT scanning with fine cuts shows the SI joint more clearly. ${ }^{2}$

\section{CONCLUSION}

The case report presented describes an anterosuperior border bridging osteophyte of the SI joint causing SI joint pain. The case illustrates the value of correlating clinical findings of SI joint pathology with CT scanning of the SI joint. Excision of the bone bridge is a relatively straight forward surgical procedure, and this case is the first such case described. Excision should only be considered in cases of symptomatic SI joint pain not responding to rehabilitation programmes and conservative treatment.

\section{Authors' affiliations}

K A Parmar, Narrabeen Sports Medicine Centre, Sydney Academy of Sport, Sydney, Australia

M Solomon, A Loefler, Prince of Wales Private Hospital, Sydney

S Dalton, North Sydney Sports Medicine Centre, Sydney

Correspondence to: Mr Parmar, Narrabeen Sports Medicine Centre, Sydney Academy of Sport, Wakehurst Parkway, Narrabeen, NSW 2101, Australia; kalparmar@rcsed.ac.uk

Accepted 29 March 2004

\section{REFERENCES}

1 Shibata $Y$, Shirai $Y$, Miyamoto $M$. The aging process in the sacroiliac joint: helical computed tomography analysis. J Orthop Sci 2002;7:12-18.

2 Vogler JB 3rd, Brown WH, Helms CA, et al. he normal sacroiliac joint: a CT study of asymptomatic patients. Radiology 1984;151:433-7.

3 Waldron T, Rogers J. An epidemiologic study of sacroiliac fusion in some human skeletal remains. Am J Phys Anthropol 1990;83:123-7.

4 Kumar B, Sriram KG, George C. Osteophyte at the sacroiliac joint as a cause of sciatica: a report of four cases. J Orthop Surg (Hong Kong) 2002;10:73-6. 